\title{
DETERMINATION OF PLASTIC LIMIT OF SOME SELECTED SOILS USING ROLLING DEVICE
}

\author{
F. Ishaque, M. N. Hoque and M. A. Rashid \\ Department of Farm Structure, Bangladesh Agricultural University \\ Mymensingh-2202, Bangladesh
}

\begin{abstract}
An attempt was made to fabricate a rolling device for determining the plastic limit of different loamy and clay soils. Five different types of soil collected from different location were used for the present investigation. Clay was taken as the yardstick of converting the soil as a continuous particle and measuring scale of this continuity was expressed in terms of clay ratio. Thus plastic limit of the soils were determined by following rolling device, Casagrande method and cone penetrometer method. It was observed that plastic limit determined by different methods have similar values for different soils and clay ratio has played important role in varying the values. Plastic limit varied from almost 20 to $25 \%$ for loamy soil having clay ratio 0.30 to 0.40 and almost 25 to $30 \%$ for clay soils having clay ratio 0.75 to 0.78 . The results revealed that values of plastic limit by rolling device method were on an average 5\% less than that of Casagrande method and almost same to that of the cone penetrometer method at different levels of clay ratio. However, the construction of rolling device has been found easy and economical. It provides perfect terminal point for accurate result. Hence it is a reliable technique for determining soil plastic limit for cohesive soil. But it is not a workable means for non-cohesive soil.
\end{abstract}

Key Words: Plastic limit, Rolling device, Clay ratio, Cone penetrometer

\section{INTRODUCTION}

Plastic limit is defined as the minimum moisture content in percentage, at which the soil crumbles, when rolled into threads of $3 \mathrm{~mm}$ in diameter. The simplest technique adopted for the determination of plastic limit is Casagrande method which has been long criticized for requiring considerable judgements from the operator and as tedious process and it is also not suitable for the sandy soil (Rashid et al., 2008). This is performed by repeated rolling of ellipsoidal-size soil mass by hand on a ground glassplate (ASTM, 1991). To overcome the inconveniences mentioned a newly developed technique was adopted by Bobrowaski and Griekspoor (1992) which has been found effective for determining plastic limit of cohesive soils. Many other researchers such as Temyingyong et al. (2002) and Rashid et al. (2008) worked with this method and found this method suitable for determining plastic limit of soils. Plastic limit is also determined by cone penetrometer method where a cone of $80 \mathrm{~g}$ weight with $30^{\circ}$ apex angle made of alluminium alloy is used (Campbell, 1976). Hence an attempt has been made to fabricate 
the rolling device and study its suitability over other methods performing tests on different cohesive soils. The discrete characteristics of soil are obtained from soil textural classification (Marshall, 1947). As the clay fraction has cohesive properties by virtue of its chemical bonds which controlled the inherent properties and productivity of soils, Witney et al. (1984) proposed that the ratio of clay to silt and sand, $C_{r}$, could be used as the practical monitor of soil type. So the percentage of clay had been taken as a measure of continuity tool which termed as clay ratio with the following expression (Ishaque, 2010).

$$
\text { Clay ratio, } \mathrm{C}_{\mathrm{r}}=\frac{\text { clay, } \%}{(\text { sand }+ \text { silt }), \%}=\frac{\text { clay, } \%}{100 \text {-clay, } \%}
$$

Henceforth it can be called as clay index for the soil productivity block of agricultural soil which lies between the clay percentages of 20 to $40 \%$.

This study on plastic limit of soil will relate the value with clay ratio. Thus this study is conducted to evaluate the performance of plastic limit rolling device with the following objectives:

To determine the clay ratio of different soils from the textural classification;

To determine the plastic limit of different loamy and clayey soils by fabricated rolling device, Casagrande method and cone penetrometer method; and

To compare the plastic limit values obtained from different methods.

\section{MATERIALS AND METHODS}

\section{Soil sample collection and preparation}

The soils were collected from different locations of Bangladesh. The locations were: Lalmai of Comilla district (Red soil Tract); Agronomy Farm of Bangladesh Agricultural University; Bhoraduba and Bhaluka village of Bhalukha Upzila, Gaghra village of Mymensingh Sadar Upazila. The soils were collected from a depth of $15 \mathrm{~cm}$ by removing the top soil. The collected soils were first dried by natural way and then pulverized by hammering. The foreign matter and vegetation were removed through sieving by IS 475 $\mu \mathrm{m}$ sieve and the screened soils were used for tests. Textural analysis of the soil was carried out by hydrometer method. The textural classes for each soil sample were then determined by plotting the values of sand, silt and clay on the Triangular diagram designed by Marshall (1947) following USDA system. The texture and type of screened soils are given in Table 1.

\section{Fabrication of plastic limit-rolling device}

A plastic limit -rolling device was fabricated using $2 \mathrm{~mm}$ and $4 \mathrm{~mm}$ laminated celluloid glass following Bobrowaski and Griekspoor (1992). A three-sided box was constructed with the dimensions shown in Fig. 1. A $4 \mathrm{~mm}$ thick laminated celluloid glass of $114.3 \mathrm{~mm}$ x $215.9 \mathrm{~mm}$ was selected as the bottom plate of the rolling device. Two pieces of $2 \mathrm{~mm}$ 
thick $25.4 \mathrm{~mm} \times 215.9 \mathrm{~mm}$ celluloid glasses were used for side elevation. At the interior intersection along the two sides and base, a celluloid rail $3 \mathrm{~mm}$ high was placed. This rail can accurately dictating the exact diameter of the soil threads. This is accomplished by placing the ellipsoidal soil masses ( 1 to 5 ) on the bottom plate. Another $4 \mathrm{~mm}$ thick celluloid glass of $101.6 \mathrm{~mm} \times 215.9 \mathrm{~mm}$ was cut for using as top plate. A handle made of aluminum was attached with the top plate.

Table 1. Texture and type of soils

\begin{tabular}{lcc|c|c}
\hline \multicolumn{1}{c}{ Locale of soil } & Sand, $\%$ & Silt, $\%$ & Clay, $\%$ & Soil Types \\
\hline Agronomy Farm, BAU & 24.04 & 63 & 12.96 & Silty loam \\
Lalmai & 34.04 & 40 & 25.96 & Loam \\
Ghagra & 5.64 & 66 & 28.36 & Silty-clay loam \\
Bhaluka & 19.00 & 38 & 43.00 & Clay \\
Bhoraduba & 20.04 & 36 & 43.96 & Clay \\
\hline
\end{tabular}

\section{Determination of plastic limit}

Water was added at different proportion with soil and thread was made of size approximate 5 to $10 \mathrm{~mm}$ initially by hand. Then this thread was placed on the bottom plate of the rolling device and the downward force was applied simultaneously with the rolling motion until the top plate comes into contact with the $3 \mathrm{~mm}$ side rails. The soil threads were then remoulded and the above procedure was repeated until the soil threads begin to crumble. From this point forward, the procedure was identical to Casagrande procedures. Plastic limits of soils were determined by Casagrande method (ASTM, 1991). Similarly, cone penetrometer was used to determine the plastic limit of these soil samples (Rahman et al., 2001).

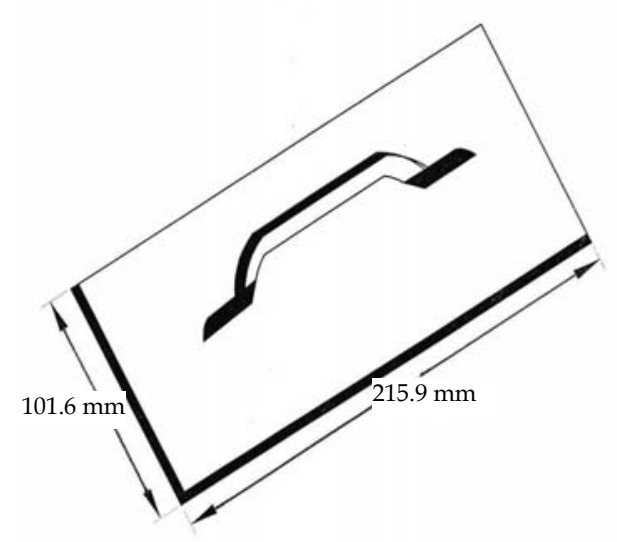

(a) Top plate

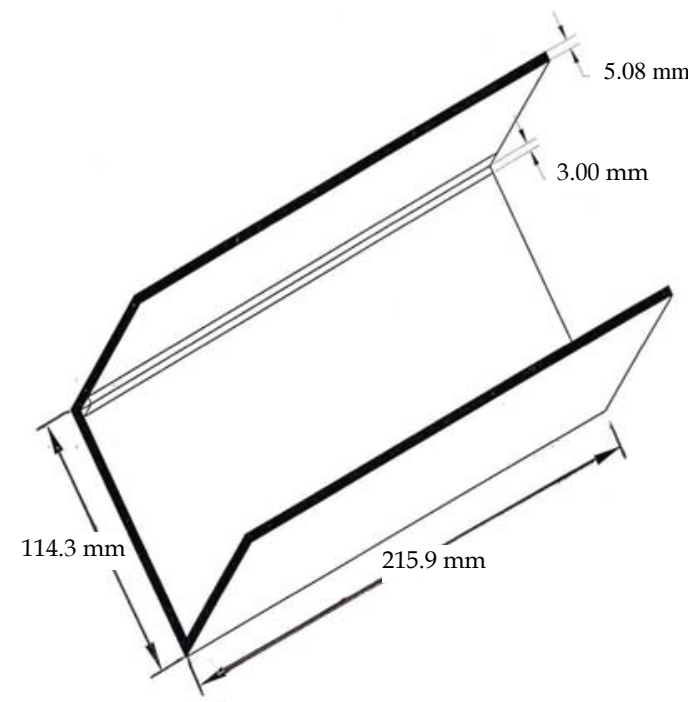

(b) Bottom plate

Fig. 1. Isometric view of the rolling device 


\section{RESULTS AND DISCUSSION}

The investigation focused on the variation of the plastic limit values of several types of loamy and clay soils of different clay ratio obtained by using three different methods. Clay ratio of soils is given in Table 2 .

Table 2. Clay index of selected soil sample

\begin{tabular}{l|l|c}
\hline \multicolumn{1}{c|}{ Location } & \multicolumn{1}{c|}{ Soil Type } & Clay Ratio \\
\hline Agronomy Farm & Silt loam & 0.31 \\
Lalmai & Loam & 0.35 \\
Gaghra & Silty clay Loam & 0.39 \\
Bhaluka & Clay & 0.75 \\
Bhoraduba & Clay & 0.78 \\
\hline
\end{tabular}

Textural classifications of these soils showed that Lalmai soil contained highest percentage of sand (34\%) whether the Gaghra soil had highest percentage of silt $(66 \%)$ and the Bhoraduba soil significantly had higher clay content (43.96\%). Except Bhaluka and Bhoraduba soil all the other corresponds to the loamy type. The loamy property in soil decreases with increasing amount of clay.

As the pore space is influenced by the partical size distribution, the clay ratio was an obvious alternative offering broader spectrum of values over the range of soil types (Elbanna, 1987). This clay ratio helps in characterizing the soil into different classes and fitting the linear model $\mathrm{C}_{\mathrm{r}}$ vs soil properties. Plastic limits of different soils obtained from different methods are given in Table 3. Fig. 2 shows the graphical representation of variation of plastic limit of different soils using different methods. The linear fitness of plastic limit curves obtained from different methods are given in Table 4.

Table 3. Plastic Limits of different soil samples obtained from different methods

\begin{tabular}{l|c|c|c|c}
\hline \multicolumn{1}{c|}{ Location } & Clay ratio & $\begin{array}{c}\text { Plastic limit by } \\
\text { casagrande } \\
\text { method, } \%\end{array}$ & $\begin{array}{c}\text { Plastic limit by } \\
\text { fabricated rolling } \\
\text { device, } \%\end{array}$ & $\begin{array}{c}\text { Plastic limit by cone } \\
\text { penetromter } \\
\text { method, } \%\end{array}$ \\
\hline Agronomy field & 0.31 & 23.00 & 20.00 & 19.5 \\
Lalmai & 0.35 & 21.13 & 21.00 & 23.0 \\
Gaghra & 0.39 & 25.28 & 24.34 & 23.0 \\
Bhaluka & 0.75 & 27.80 & 26.50 & 27.0 \\
Bhoraduba & 0.78 & 29.91 & 30.00 & 31.0 \\
\hline
\end{tabular}

The results reveal that for cohesive soil plastic limit determined by rolling device provides more variation than Casagrande method and produces the value nearest to cone penetrometer. In contrast with the Casagrande method, rolling device produce exact 
point of cracking and accurate diameter of threads which is undoubtedly more acceptable than the Casagrande method. For field experiment using this device is more suitable for cohesive soil and less effective in non-cohesive soil.

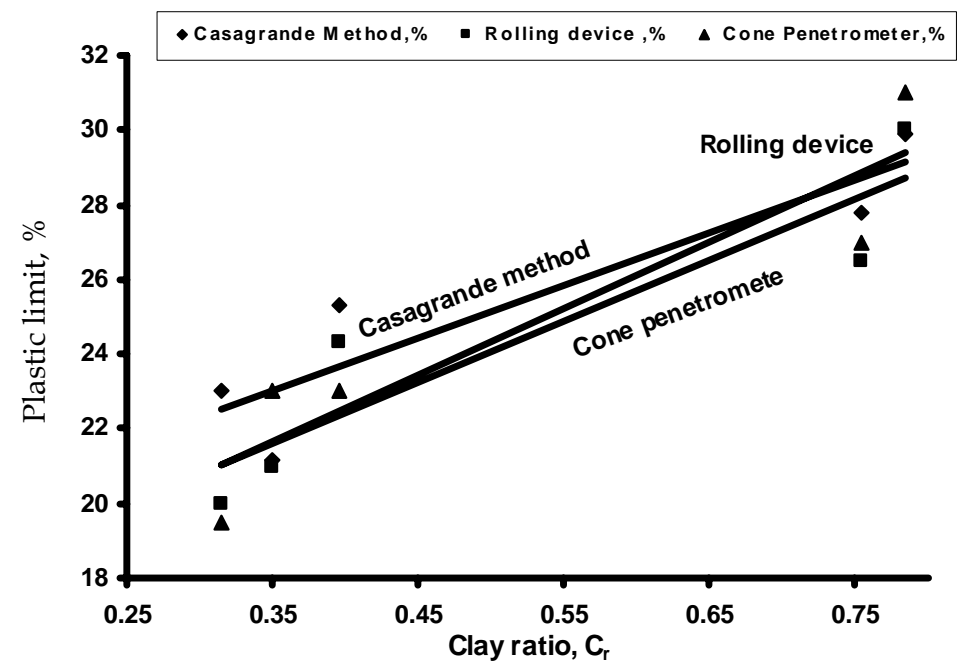

Fig. Variation of plastic limits of differ soil samples obtained from different methods

Table 4. Linear fitness of the plastic limit curves

\begin{tabular}{lcc}
\hline \multicolumn{1}{c|}{ Plastic limit determination methods } & Relationship (linear) & Fitness, $\mathrm{r}^{2}$ \\
\hline Rolling device & YPLR $=0.1640 \mathrm{x}+15.841$ & 0.8501 \\
Casagrande method & yPLs $=0.1401 \mathrm{x}+18.172$ & 0.8285 \\
Cone penetrometer method & yPLp $=0.1787 \mathrm{x}+15.405$ & 0.8685 \\
\hline
\end{tabular}

\section{Comparison of plastic limit values obtained from different methods}

Comparative study of plastic limit values obtained different methods is given in Table 5.

Table 5. Comparative study of plastic limit by different methods

\begin{tabular}{|c|c|c|c|c|c|}
\hline \multirow[t]{2}{*}{ Clay ratio } & \multicolumn{3}{|c|}{ Plastic limit, \% } & \multirow{2}{*}{$\begin{array}{c}\text { Difference, } \% \\
\text { (Rolling device } \\
\text { to casagrande } \\
\text { method) }\end{array}$} & \multirow{2}{*}{$\begin{array}{c}\text { Difference, } \% \\
\text { (Rolling device to } \\
\text { cone penetrometer } \\
\text { method) }\end{array}$} \\
\hline & $\begin{array}{l}\text { Rolling } \\
\text { device }\end{array}$ & $\begin{array}{c}\text { Casagrande } \\
\text { method }\end{array}$ & $\begin{array}{c}\text { Cone } \\
\text { penetrometer } \\
\text { method }\end{array}$ & & \\
\hline 0.31 & 20.00 & 23.00 & 19.5 & 15.0 & 2.50 \\
\hline 0.35 & 21.00 & 21.13 & 23.0 & 00.6 & 9.52 \\
\hline 0.39 & 24.34 & 25.28 & 23.0 & 03.8 & 5.50 \\
\hline 0.75 & 26.50 & 27.80 & 27.0 & 04.9 & 1.88 \\
\hline 0.78 & 30.00 & 29.91 & 31.0 & 00.3 & 3.33 \\
\hline
\end{tabular}


Referring to the Table 5, the rolling device method always produces less value of plastic limits than those of the Casagrande method for the clay ratio of 0.31 to 0.78 . It was observed that the values were almost same to those from the Casagrande method except for clay ratio $31.51 \%$. It was also observed that values from rolling device and those from cone penetrometer method are very close and the variation was 2 to $10 \%$. These results proved that the suitability of rolling device technique.

Linear relationships of plastic limits determined by rolling device method with other methods are given in Fig. 3.

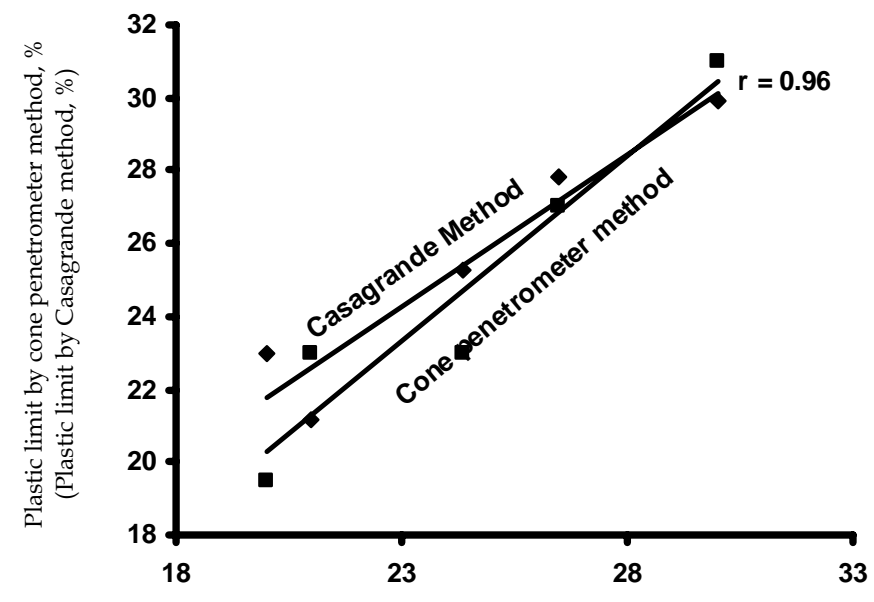

Plastic limit by rolling device, $\%$

Fig. 3. Linear relationship of plastic limit by rolling device with other method

This graph revealed that plastic limits by rolling device have a good correlation with those values of Casagrande method and cone penetrometer method.

\section{Pictorial presentation of threads produced by plastic limit}

Thread produced by plastic Limit rolling device is exact $3 \mathrm{~mm}$ diameter while it is difficult to ensure exact diameter in Casagrande method. Pictorial representations are given below, in Fig. 5.

From this observation it is suggested to use the rolling device in determining the plastic limit. It is to be pointed out that the cost of the device is about Tk.200. It is also a very simple and very easy to fabricate. 


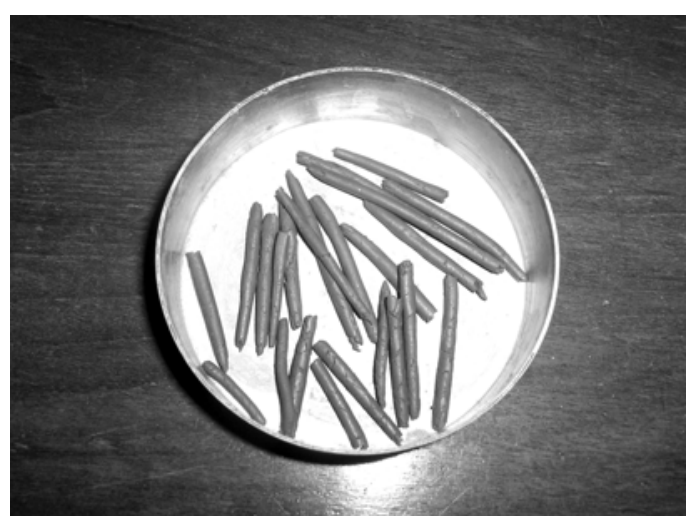

(a) Thread produced by casagrande method

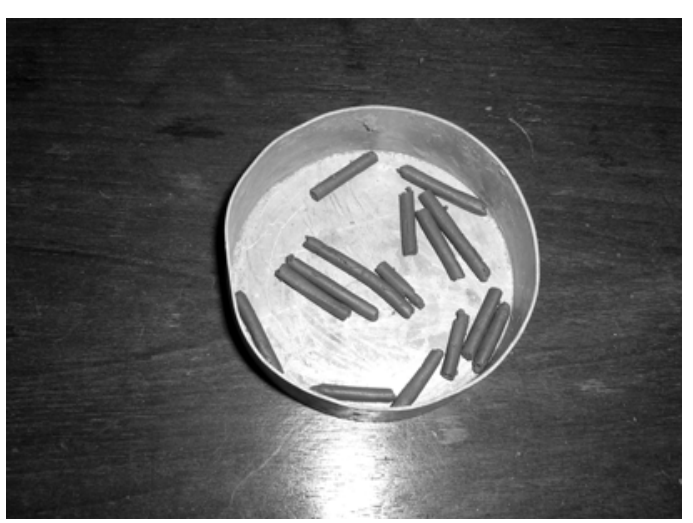

(b) Thread produced by rolling device

Fig. 5. Threads produced by casagrande method and rolling device method

\section{CONCLUSION}

The linear model of clay ratio versus soil properties has been developed on the basis of soil type in the form of clay ratio which helps to test the suitability of the rolling device over other methods to determine the plastic limit. Rolling device has been found suitable to determine the values. The plastic limits of cohesive soil obtained from this device are almost same to those obtained from Casagrande method and cone penetrometer method. These values are well correlated. This method is of less operator dependent and expected to be more feasible means of measuring plastic limit. But this technique is incompatible for non-cohesive soils. Hence the rolling device could be successfully applied for measuring plastic limit of cohesive soils.

\section{REFERENCES}

ASTM. 1991. Standard test method for liquid limit, plastic limit, and plasticity index of soils, (D4318-84).Annual Book of ASTM Standards, 04.08, American Society for Testing and materials, Philadelphia. 608-618.

Bobrowski, L. J., Jr. and Griekspoor, D. M. 1992. Determination of the plastic limit of soil by means of a rolling device. Geotechnical Testing J. 15(3): 284-287.

Campbell, D.J. 1976. Plastic limit determination using a drop cone penetrometer. J. Soil Sci., 27: 295-300.

Elbanna, E. B. and Witney, B. D. 1987. Cone penetration resistence equation as a function of the clay ratio, soil moisture content and specific weight. J. Terramechanics, 24(1): 41-56.

Ishaque, F. 2010. Consistency limits of some selected soils using different methods. Unpublished. M.S. Thesis, Dept. of Farm Structure, Bangladesh Agricultural University, Mymensingh.

Marshall, T. J. 1947. Mechanical composition of soil in relation to field descriptions of texture. Council for Scientific and Industrial Research, Bulletin No. 224, Melbourne. 
Rahman, M. Z., Rashid, M. A. and Abedin, M. Z. 2001. Determination of soil consistency limits by modified cone-enetrometer. Bangladesh J. Agri. Engg., 12(1): 81-86.

Rashid, A. S. A., Kassim, K. A., Katimon, A. and Noor, M. N. 2008. Determination of plastic limit of soil using modified methods. Malaysian J. Civil Engg., 20(2): 295-305.

Temyingyong, A., Chantawarangul, K. and Sudasna-na-Ayudthya, P. 2002. Statistical analysis of influenced factors affecting the plastic limit of soils. Kasetsart J. (Nat. Sci.), 36: 98-102.

Witney, B. D., Elbanna, E. B. and Eradatoskoui, K. 1984. Tractor power selection with compaction constrains. Proc. $8^{\text {th }}$ Int. Conf., Int. Soc. Terrain Vehical Systems 11, 761-773. 